\title{
Literature Review on Fingerprint Level 1 and Level 2 Features Enhancement to Improve Quality of Image
}

\author{
Krishna Prasad. K. ${ }^{1}$ and P. S. Aithal ${ }^{2}$ \\ ${ }^{1}$ Research Scholar, College of Computer and Information Science, Srinivas University, \\ Mangaluru-575001, Karnataka, India \\ ${ }^{2}$ College of Computer and Information Science, Srinivas University, Mangaluru-575001, \\ Karnataka, India \\ E-Mail: karanikrishna@gmail.com
}

Type of the Paper: Literature Review.

Type of Review: Peer Reviewed.

Indexed in: OpenAIRE.

DOI: http://dx.doi.org/10.5281/zenodo.835608.

Google Scholar Citation: $\underline{\text { IJMTS }}$

\section{How to Cite this Paper:}

K., Krishna Prasad, Aithal, P. S. (2017). Literature Review on Fingerprint Level 1 and Level 2 Features Enhancement to Improve Quality of Image. International Journal of Management, Technology, and Social Sciences (IJMTS), 2(2), 8-19.

DOI: http://dx.doi.org/10.5281/zenodo.835608.

International Journal of Management, Technology, and Social Sciences (IJMTS) A Refereed International Journal of Srinivas University, India.

(C) With Authors.

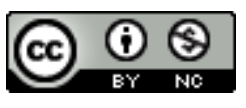

This work is licensed under a Creative Commons Attribution-Non Commercial 4.0 International License subject to proper citation to the publication source of the work.

Disclaimer: The scholarly papers as reviewed and published by the Srinivas Publications (S.P.), India are the views and opinions of their respective authors and are not the views or opinions of the SP. The SP disclaims of any harm or loss caused due to the published content to any party. 


\title{
Literature Review on Fingerprint Level 1 and Level 2 Features Enhancement to Improve Quality of Image
}

\author{
Krishna Prasad. K. ${ }^{1}$ and P. S. Aithal ${ }^{2}$ \\ ${ }^{1}$ Research Scholar, College of Computer and Information Science, Srinivas University, \\ Mangaluru-575001, Karnataka, India \\ ${ }^{2}$ College of Computer and Information Science, Srinivas University, Mangaluru-575001, \\ Karnataka, India \\ E-Mail: karanikrishna@gmail.com
}

\begin{abstract}
Biometrics is the one most popular property in human distinguishing proof based on physical or behavioral features. The different physiological characteristics are Fingerprint, DNA, Face, hand, retina, ear features, and odor, where as behavioral characteristics or features are typing rhythm, gait, gesture, and voice with the basic premise that all are unique and all human beings are identified by these intrinsic traits. In the physiological traits, Fingerprint is most commonly utilized the biometric feature in diverse fields for identification and verification purpose. Fingerprint features can be separated into three noteworthy classifications in view of the granularity at which they are removed as level 1, level 2, and level 3 features. Level 1 feature contains macro details, which are easily extractable and include orientation filed, ridge frequency filed and pattern configuration. Only these global features or Level 1 features are not sufficient to uniquely identify or recognize, but if these features are used along with level 2 or level 3 features, that can make the fingerprint recognition system more robust and secure. Level1 features are used for image enhancement and orientation purpose. In this paper, we made a survey of existing literature on Level 1 features and try to analyze other researcher's contribution to this field.
\end{abstract}

Keywords: Fingerprint Recognition, Ridge Orientation, Ridge Ending, Bifurcation, Level 1 Features.

\section{INTRODUCTION :}

Fingerprint recognition is one of the interesting and complex image processing problems, which requires a constant and continuous contribution to new research from the research community. Even though the face recognition is automatic pattern recognition system and controlled by the computer, the performance of the system is directly dependent on the quality of the fingerprint images and the quality of the image capturing device [1]. Partial fingerprint image captured by the image acquisition device is yet another problem faced by the automatic fingerprint pattern recognition system. Level1 details may include general outlier structure of ridges like ridge flow and ridge pattern configuration [2]. Level 1 feature comprises of the orientation of the fingerprint, core-center from which ridge ending and ridge pattern named and delta location-point on the friction ridge and distinction of finger versus palm. As shown in figure 1, Level1 Features example includes Simple Arch, Tented Arch, Right Loop, Left Loop, Composite Whorl, Concentric Whorl, Imploding Whorl, Press Whorl, Spiral Whorl, Peacock's- Eye Whorl and Variant Whorl [3]. Loop pattern Ridges enters from either side of the impression or pattern, re-curves or touches an imaginary line drawn from delta to the core and terminates on the same side from where it's originated. In Arch, pattern ridges start from one side of the fingerprint pattern to another side 
without doing backward turn. Whorl pattern consists of series of circles which starts from an arbitrary point and ends at the same point [3].

with only Level 1 features, fingerprint recognition systems neither recognize the image
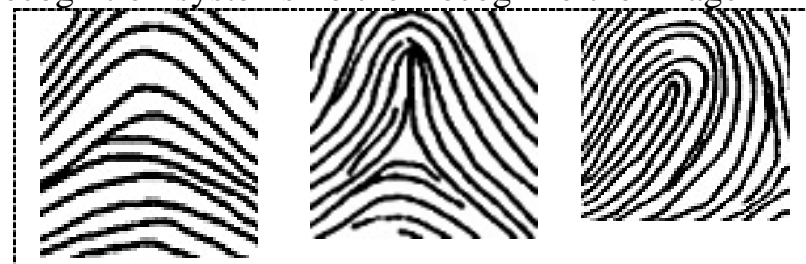

Simple Arch
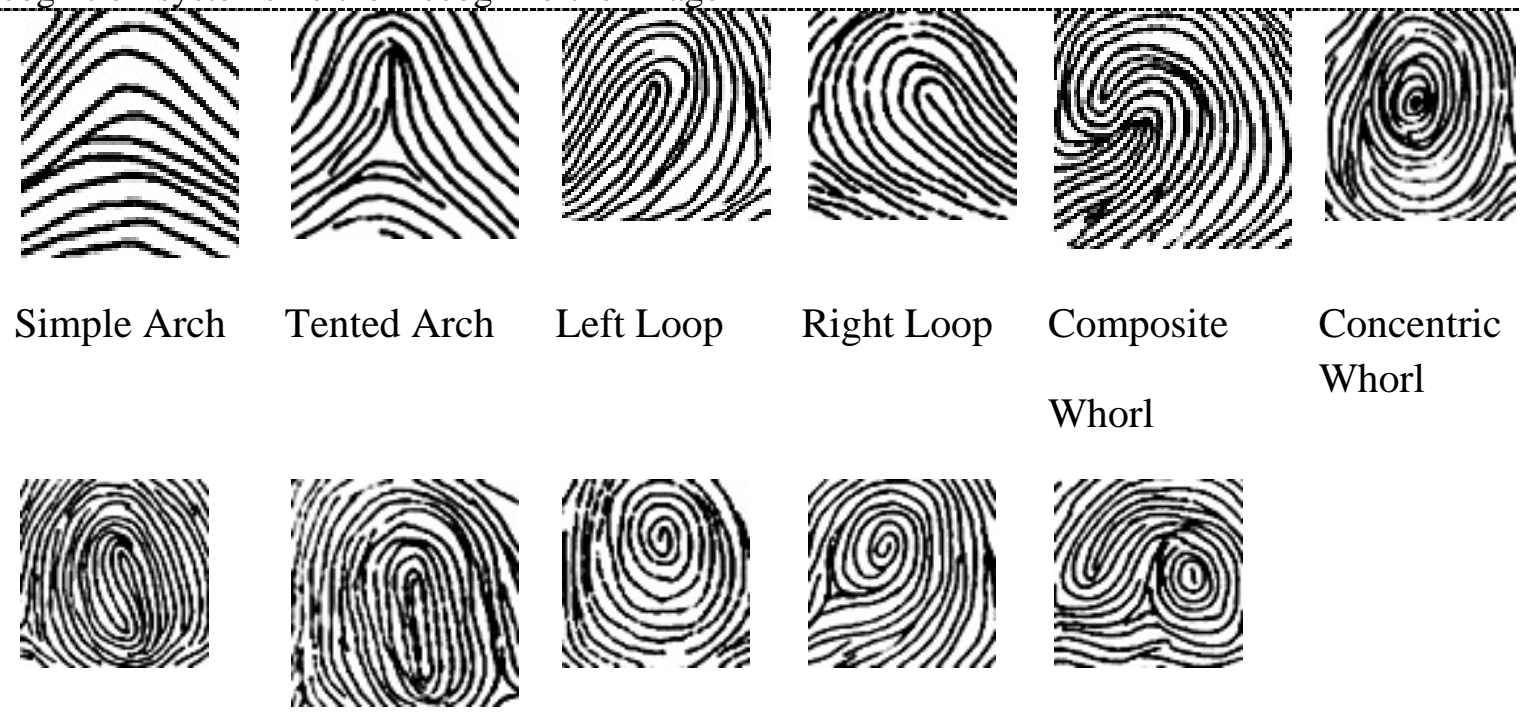

Imploding

$\begin{array}{ll}\text { Press Whorl } & \text { Spiral } \\ & \text { Whorl }\end{array}$

nor identify or verify the image [4]. Level 1 feature is mainly used for classification, verification, filtering, and enhancement purpose.
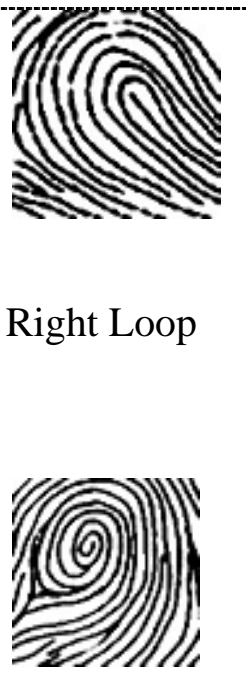

Composite Whorl

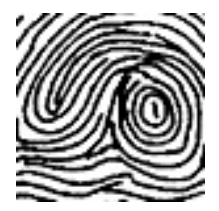
Peacock's-
Variant
Eye Whorl
Whorl

\section{Figure 1: Fingerprint Level 1 Features-Examples [2-3]}

The main purpose of Level 1 features- ridge pattern or flow and orientation are mainly used for image enhancement and orientation purpose, which will improve the quality of fingerprints. If the image contains noisy regions, it's difficult to define the orientation of the image. Image enhancement techniques are essential or necessary due to the fact that, the image captured through sensor or optical device is not assured quality [4]. Fingerprint image enhancement is technically done by improving the quality of ride pattern or increasing the consistency of ridge orientation, which literally means level 1 feature, is exposed and analyzed. Ridge ending and ridge bifurcation or minutiae points are level 2 features. Micro details like pore and ridge contours form level 3 features. Figure 2 shows fingerprint features in terms of level 1, level 2, and level 3.

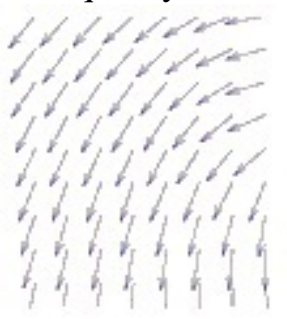

Level 1

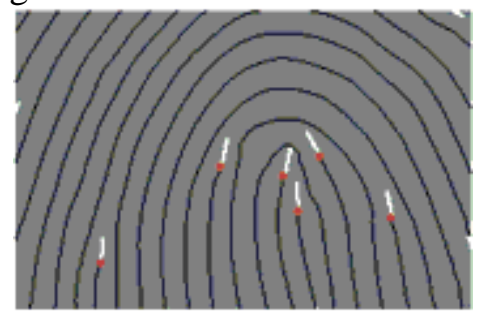

Level 2

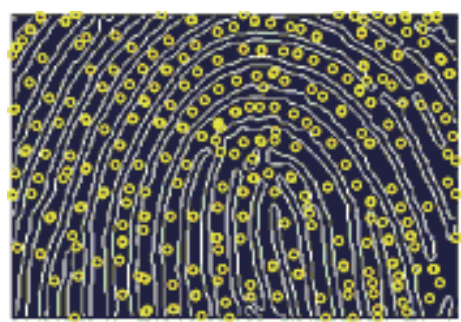

Level 3

Figure 2: Three Levels Features of Fingerprint [5] 
A fingerprint has several features, which are island (a line that runs or flows alone without touching other lines or regions), dot (an independent ridge which looks like a dot and equal in length and width), bridge or crossover (a small ridge which connects two parallel ridges), core (centre of the fingerprint pattern) and delta (a point from which fingerprint pattern alters or deviates). The unique features of a ridge, from which different pattern occurs are called minutiae. Ridge ending and ridge bifurcation are the two types of minutiae. A ridge ending is nothing but where ridge terminates or discontinue. Ridge bifurcation is a feature where a ridge splits or diverges, like a fork. From ridge ending and bifurcation, we can define several other features. The lake or enclosure is a feature in this ridge diverges and soon converges and becomes single ridge. Spur is yet another feature in which short ridge branching off a long ridge. Still, some other features like line unit, line fragment, eye, and hook also can be extracted and studied, which are referred as fingerprint low-level features. The low-level features are shown in figure 2.

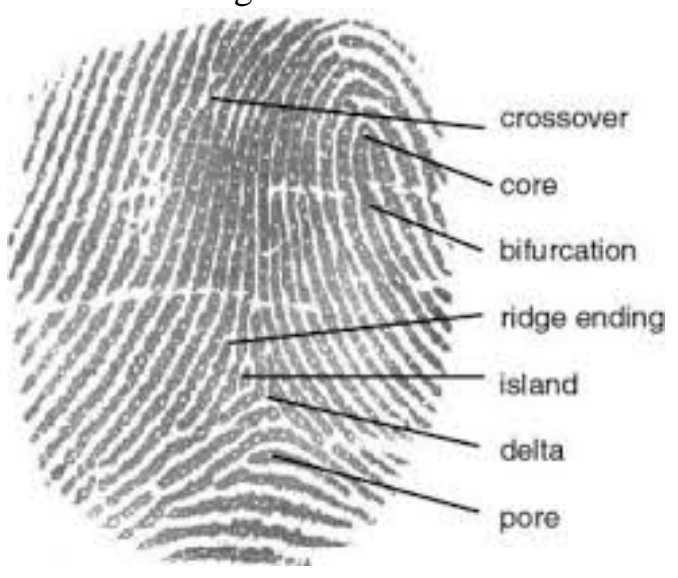

Figure 3: Low- level Features of Fingerprint image [5]

Level 2 features show various ways ridge points can be irregular. Minutiae are most reliable features, which are permanent and unique for every human being unless and until some wound or permanent damage occurs. The number of minutiae points collected should be more to get high efficiency. Examples of level 2 features are shown in figure 4.

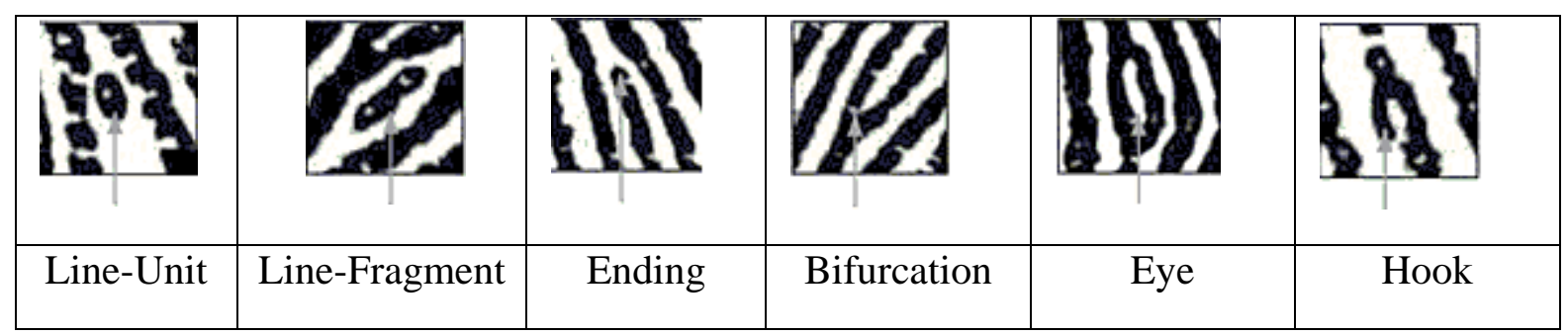

Figure 4: Examples of Level 2 features of fingerprint [6]

In this paper, we discuss the contribution of other researchers in feature extraction process of fingerprint images using Level 1 or Level 2 features or sometimes both, and how these features are helpful in broad classification of fingerprint images or in the enhancement of images by reducing noise. We also do a quantitative analysis of fingerprint image enhancement using a table which lists Author name, Exposed feature level, Approaches/ Techniques used, and Benefits as its columns. 


\section{LITERATURE REVIEW :}

This section narrates work done by other researchers to Fingerprint enhancement through classification using Level 1 or Level 2 features or sometimes both. In this section, the contributions of all researchers to the field of fingerprint image enhancement using Level1 features are summarized.

Sherlock et al. (1994) [7] proposed image enhancement algorithm based on nonstationary directional Fourier domain filtering. The directional filter used first and foremost to smooth the input image whose orientation in all fields matched to the local ridge orientation. The output of this stage is reduced noise image or high-quality image compared to the input image. Fourier Domain filtering mainly uses local ridge patterns and local ridge parameters, directional band pass filters, and local ridge spacing. To implement the filtering techniques in the digital computer the image must be spatially sampled and the continuous function used in Fourier Transform is replaced by discrete functions. All images were sampled at a low resolution of 512 by 512 pixels and edge effects of discrete Fourier Transform were reduced to $10 \%$ using separable split-cosine window. The result of the enhancement used for various classifications of the input images. A comparison is made between enhancements used in automated fingerprint identification system developed by the UK home office and enhancements made based on this filter method and the later one showed significant advances in speed, accuracy, and efficiency of the automated fingerprint identification system. Chikkerur et al. (2005) [8] proposed fingerprint enhancement using Short Term Fourier Transforms (STFT), which is based on not stationary signals. In this paper, researchers extended the properties of STFT to two dimensional (2D) fingerprint images. They proposed a new algorithm for image enhancement process based on contextual filtering in Fourier domain. The new algorithm simultaneously yields local ridge orientation and local ridge frequency level 1 feature. The intrinsic features of the fingerprint image can be computed using single unified approach rather than multiple algorithms. Compare to other image processing algorithm like local/windowed processing, more formal approach for analyzing the non-stationary fingerprint image.

Hsieh, C. T. et al. (2003) [9] proposed an effective and efficient algorithm for fingerprint image enhancement, which not only improves the quality of the clarity of the image but also improves the continuity of the ridge structure based on global texture and local orientation. The global texture is exposed using multi resolution analysis and local orientation through wavelet transforms. In wavelet based fingerprint analysis first input image is converted into normalized image. Normalized image is decomposed using wavelet decomposition. Wavelet decomposition image is processed again using global texture filtering. Next Local directional compensation is done and finally, wavelet reconstruction process is achieved. Normalization, Wavelet decomposition, Global texture filtering, Local directional compensation, wavelet reconstruction are the flowchart components of proposed enhancement algorithm. Their Experiment results show that enhanced image using wavelet based enhancement algorithm out performed in terms of efficiency and execution time in improving minutiae detection. Paul \& Lourde (2006) [10] proposed the new method for image enhancement using the applications of wavelet transforms. Before the inventions of these techniques, popular other techniques were Gabor filtering and Fourier filtering. The new method outperformed compared to this method in terms of efficiency and execution time.

Ye et al., 2007 [11] additionally utilized a 2D discrete wavelet transform to digitally compress fingerprint and to reconstruct the original image, whenever necessary using some reconstructing attributes. Few quantitative measurements are used to evaluate the quality of wavelet transform, which helps in image enhancement process. In this paper researcher also used a different measure to evaluate the performance of wavelet transform and obtained higher efficiency. Farina et al., (1999) [12] worked on a binary image, the input is either already taken as a binary image or converted into binary from the greyscale image and also the image is 
skeletonised. Due to differences in a number of minutiae occur in real, there is a necessity of post pre-processing, in order to maintain the consistency of image and to reduce the computational cost. They also proposed a new method for ridge cleaning based on ridge positions. In order to validate endpoints and bifurcation, they used two novel approaches and related algorithm. The presented minutiae extraction algorithm performs well in dirty areas and on the backgrounds.

Maio and Maltoni, 1997 [13] focused on the extraction of ridge ending and bifurcation called as minutiae directly from the gray-scale image rather than converting it into the binary image and then extracting minutiae. The new techniques were based on ridge line following algorithms and algorithm follows or goes parallel along with ridge line until ridge ending or bifurcation occurs. They compared their algorithm with those known approaches, which converts the original image into binary image and new method showed superiority in terms of efficiency and robustness.

Hong et al. (1998) [14] presented a fast fingerprint enhancement algorithm based on level features like fingerprint ridge pattern and orientation and substantially improve the quality of ridge and furrow structures on the estimated local ridge orientation and frequency. This is one of most cited journal paper in image enhancement process. They have evaluated the performance of the image enhancement algorithm using goodness index evaluation criteria of minutiae and by comparing the accuracy of online fingerprint system for verification purpose. They used Gabor filter to tune local ridge orientation and ridge frequency. Gabor Filters (Gabour, 1946 [15]) combines both frequency domain and spatial domain with a better-combined resolution by utilizing both frequencies selective and orientation selective. Gabor filters help to retain the true valley and ridge structure and also helps to remove maximum noise involved in the input image. Hong et al. (1996) [16] proposed new fingerprint enhancement algorithm which comprises of different phases as orientation filed estimation, ridge extraction, and minutiae extraction and preprocessing. These phases help to decompose input image to set of filtered image. Yang et al. (2003) [17], authors proposed novel filter method for fingerprint image enhancement by considering traditional Gabor Filtering as the inspiration for their work. They mainly developed with the intention to overcome the flaws encountered in traditional Gabor filter and name it as Modified Gabor Filter (MGF) with parameter selection scheme is image independent. Experimental results showed that MGF reduces False Rejection Rate (FRR) by 2\% and False Acceptance Rate (FAR) of $0.01 \%$.

Greenberg et al. (2000) [18] proposed two methods for fingerprint image enhancement, out of which one method is histogram equalization and the other one is an anisotropic filter for direct greyscale enhancement without converting to a binary image. The result achieved is compared with some other similar image enhancement algorithm, and new algorithm outperformed in terms of efficiency and time required. Wu et al. (2004) [19] proposed a new method for image enhancement, by integrating Anisotropic filter and Directional Median Filter (DMF). Anisotropic filter and DMF are used to reduce Gaussian distributed noise and impulse noise. DMF helps to join broken fingerprint ridges, corrects the holes of fingerprint images, and smoothes irregular ridges. In order to implement and test the algorithm, FVC2000 database were used. They compared their new algorithm with the already existing similar algorithm and results showed good performance in efficiency and execution time.

Teddy and Martin (2002) [20] demonstrated spatial analysis techniques for latent fingerprint image enhancement. The latent fingerprint is not good in quality which includes some degrade quality like blurred, incomplete or partial and also their spatial definition is not clear.

In order improve the quality and thereby by achieving classification or comparison, they used some nonlinear filters and frequency domain filters along with high-pass Butterworth filter with the aid of adaptive fast Fourier transform for enhancement of the degraded image. Fingerprint captured using ink or live 
scan usually requires only spatial filtering like brightness, contrast, and color map adjustment to examine the level 2 features.

E-Kyung and Bae (2006) [21] proposed an adaptive filter according to different conditions of the input image which are oil, dry, and neutral instead of the uniform image. To identify oil/dry/neutral image five features are used which are mean, variance, block directional difference, ridge and valley thickness ratio, and orientation change. In adaptive filtering first, several features of the image are extracted and then it is fed into clustering module and then adaptive filtering is applied on clustering to produce a good quality image. For clustering wards clustering method is used. After clustering, once the image is processed depending on the image characteristics, for oily images valleys are improved by expanding thin and detached one, for dry images ridges are enhanced by extracting their center lines and removing white pixels.

Chengpu et al. (2008) [22] proposed an effective robust algorithm for fingerprint enhancement and firstly, used contrast stretching approach to improve the clarity between foreground and background of the fingerprint image. Secondly, to improve the orientation estimation utilized the structure of the tensor property. Finally, in order to take the advantages both Gabor filter and diffusion filter, they are combined and adopted low pass filter at the direction that is parallel to the ridge and used band pass filter at the direction perpendicular to the ridge. Wang, $\mathrm{Li}$, Huang, \& Feng, 2008 [23] introduced log Gabor filter in order to overcome drawbacks of the traditional Gabor filter and to promote and improve fingerprint enhancement performance. The result showed good performance and efficiency compare to traditional Gabor filter. Yuanyuan (2012) [24] proposed new image enhancement algorithm based on elliptical Gabor filter. The ridge information on the fingerprint is used for determining the range of filtering dynamically. Estimating the degree of curvature and the frequency of fingerprint ridge in local areas are used for accomplishing elliptical Gabor filter. To correct errors in the input image and to obtain more precise enhancement, elliptical Gabor filter is used. The experimental results show that the precision of minutiae extraction is significantly improved and which results in good and higher accuracy rate of the subsequent operations are also improved.

Babatund (2012) [25] modified some of the existing sub-models mathematical algorithms for fingerprint image enhancement and obtained new version. The different sub models of the new version are segmentation, normalization, ridge orientation estimation, ridge frequency estimation, Gabor filtering, and Binarization and Thinning. In order to test this new version, the author used windows vista home basic operating system and Matrix Laboratory (Matlab) as Frontend engine. Synthetic fingerprint and real fingerprint were used while testing in FVC2004 fingerprint database DB3. The new version performed well in terms of efficiency and some other commonly used performance evaluation matrices.

Saatci \& Tavsanoglu (2003) [26] concentrated on the segment by segment analysis of the fingerprint pattern results in various ridge directions and frequencies. To match ridge features at each point authors used directional filter along with correct filter parameters and which resulted in effective fingerprint ridge enhancement. Researchers used main technique or method for image enhancement is Cellular Neural Network (CNN) Gabor type filters. He, Tian, Luo, \& Zhang, (2003) [27] developed fingerprint image enhancement algorithm based on orientation fields with three aspects as ridge information for minutiae matching process in a simple and effective way, use of variable sized boundary boxes, and use of simpler alignment method. The first aspect overcomes the problem of reference point per selection with low computational cost. The second aspect makes the algorithm more robust to nonlinear deformation between fingerprints. The third approach reduces the complexity of alignment.

\section{QUALITATIVE ANALYSIS OF FINGERPRINT LEVEL 1 AND LEVEL 2 FEATURES ENHANCEMENT :}


Fingerprint image enhancement is one of the main process or stage of Automatic Fingerprint Recognition System. The performance of fingerprint recognition system is depending on the quality of the input image. Partial fingerprint draws special attention for fingerprint image enhancement, due to its inherent properties like broken, cut, damage or noisy. So there is a great necessity of image enhancement process in order to enhance the performance of automatic fingerprint recognition system. This section presents different approaches to image

Table 1: Comparative Analysis of Fingerprint Image Enhancement by extracting Level 1 and Level 2 Features

\begin{tabular}{|c|c|c|c|}
\hline Authors & $\begin{array}{l}\text { Exposed } \\
\text { Features } \\
\text { (Level/s) }\end{array}$ & $\begin{array}{l}\text { Approaches } \\
\text { /Techniques }\end{array}$ & Benefits \\
\hline $\begin{array}{l}\text { Sherlock et } \\
\text { al. (1994) } \\
\text { [7] }\end{array}$ & Level 1 & $\begin{array}{lll}\text { Directional Fourier } & \text { Domain } \\
\text { Filtering } & & \\
\end{array}$ & $\begin{array}{l}\text { Demonstrates the usefulness of position- } \\
\text { dependent Fourier domain in processing } \\
\text { of images } \\
\text { Significant improvements in the speed } \\
\text { and accuracy of AFIS }\end{array}$ \\
\hline $\begin{array}{l}\text { Chikkerur } \\
\text { et al. } \\
(2005)[8]\end{array}$ & Level 1 & $\begin{array}{l}\text { Short Term Fourier } \\
\text { Transforms, } \\
\text { Contextual filtering in Fourier } \\
\text { domain }\end{array}$ & $\begin{array}{l}\text { Fingerprint image can be computed } \\
\text { using single unified approach. } \\
\text { More formal approach for analyzing the } \\
\text { non-stationary fingerprint image. }\end{array}$ \\
\hline $\begin{array}{l}\text { Hsieh, C. } \\
\text { T. et al. } \\
(2003)[9]\end{array}$ & $\begin{array}{l}\text { Level } 1 \& \\
\text { Level } 2\end{array}$ & $\begin{array}{lll}\text { Wavelet } & \text { Transform, Gabor } \\
\text { Filters } & \end{array}$ & $\begin{array}{l}\text { Enhanced image using wavelet based } \\
\text { enhancement algorithm out performed in } \\
\text { terms of efficiency and execution time } \\
\text { in improving minutiae detection. } \\
\text { Images are normalized and reduced } \\
\text { noise. }\end{array}$ \\
\hline $\begin{array}{l}\text { Paul \& } \\
\text { Lourde } \\
(2006)[10]\end{array}$ & $\begin{array}{l}\text { Level } 18 \\
\text { Level } 2\end{array}$ & $\begin{array}{lll}\text { Wavelet } & \text { Transform, Gabor } \\
\text { Filters, } & \end{array}$ & $\begin{array}{l}\text { Enhanced performance, efficiency, and } \\
\text { execution time compared to traditional } \\
\text { Gabor filter and Fourier filter }\end{array}$ \\
\hline $\begin{array}{l}\text { Ye et al., } \\
2007[11]\end{array}$ & $\begin{array}{l}\text { Level } 1 \& \\
\text { Level } 2\end{array}$ & $\begin{array}{ll}\text { Wavelet Transform, Gabor } \\
\text { Filters, }\end{array}$ & $\begin{array}{l}\text { Quantitative measurements used to } \\
\text { evaluate the quality of wavelet transform } \\
\text { helps in image enhancement process. } \\
\text { Enhanced performance and efficiency }\end{array}$ \\
\hline $\begin{array}{l}\text { Farina et } \\
\text { al., (1999) } \\
{[12]}\end{array}$ & $\begin{array}{lrr}\text { Level } & 2 & \& \\
\text { Level } & 1 \\
\text { (partially) } & \end{array}$ & Binarisation & $\begin{array}{l}\text { Reduced computational cost due to post } \\
\text { pre-processing. Ridge cleaning based on } \\
\text { ridge positions }\end{array}$ \\
\hline $\begin{array}{l}\text { Maio and } \\
\text { Maltoni, } \\
1997[13]\end{array}$ & Level 2 & $\begin{array}{l}\text { Gray scale image is directly } \\
\text { processed }\end{array}$ & $\begin{array}{l}\text { Compared to known approaches, which } \\
\text { converts the original image into binary } \\
\text { image and new method showed } \\
\text { superiority in terms of efficiency and } \\
\text { robustness. }\end{array}$ \\
\hline Hong et al. & Level 1 & Ridge pattern and orientation, & Fast fingerprint enhancing algorithm. \\
\hline
\end{tabular}

enhancement using level 1 or level 2 or both features of the fingerprint image. Table 1 gives a detailed description of fingerprint image enhancement algorithms or methods. Most of the algorithms consider either Level 1 or Level 2 or both features for image enhancement purpose. The table narrates Author name, Exposed Features, Approaches/Techniques, and Benefits, of fingerprint image enhancement algorithms. 
International Journal of Management, Technology, and Social

\begin{tabular}{|c|c|c|c|}
\hline (1998) [14] & & Goodness Index, Gabor Filter & $\begin{array}{l}\text { Local ridge orientation and ridge } \\
\text { frequency which improves the } \\
\text { performance of the matching process. }\end{array}$ \\
\hline $\begin{array}{l}\text { Gabour, } \\
1946[15])\end{array}$ & $\begin{array}{l}\text { Level } 1 \& \\
\text { Level } 2\end{array}$ & $\begin{array}{l}\text { Gabor filter, frequency } \\
\text { domain, spatial domain }\end{array}$ & $\begin{array}{l}\text { Helps to retain the true valley and ridge } \\
\text { structure and also helps to remove } \\
\text { maximum noise involved in the input } \\
\text { image. }\end{array}$ \\
\hline $\begin{array}{l}\text { Hong et al. } \\
\text { (1996) [16] }\end{array}$ & $\begin{array}{l}\text { Level } 1 \quad \& \\
\text { Level } 2\end{array}$ & Gabor Filter & $\begin{array}{l}\text { Helps to decompose input image to set } \\
\text { of filtered image. } \\
\text { Comprises of different phases as } \\
\text { orientation filed estimation, ridge } \\
\text { extraction, and minutiae extraction and } \\
\text { preprocessing. }\end{array}$ \\
\hline $\begin{array}{l}\text { Yang et al. } \\
\text { (2003) [17] }\end{array}$ & $\begin{array}{l}\text { Level } 1 \quad \& \\
\text { Level } 2\end{array}$ & Modified Gabor Filter (MGF) & $\begin{array}{l}\text { MGF reduces False Rejection Rate } \\
\text { (FRR) by } 2 \% \text { and False Acceptance } \\
\text { Rate (FAR) of } 0.01 \% \text {. }\end{array}$ \\
\hline $\begin{array}{l}\text { Greenberg } \\
\text { et } \quad \text { al. } \\
(2000) \text { [18] }\end{array}$ & $\begin{array}{l}\text { Level } 1 \quad \& \\
\text { Level } 2\end{array}$ & $\begin{array}{l}\text { histogram equalization and } \\
\text { Anisotropic filter }\end{array}$ & $\begin{array}{l}\text { Direct grayscale enhancement without } \\
\text { converting to a binary image. New } \\
\text { algorithm outperformed in terms of } \\
\text { efficiency and time required. }\end{array}$ \\
\hline $\begin{array}{l}\text { Wu et al. } \\
(2004)[19]\end{array}$ & $\begin{array}{l}\text { Level } 1 \& \\
\text { Level } 2\end{array}$ & $\begin{array}{lrr}\text { Anisotropic } & \text { filter } & \text { and } \\
\text { Directional } & \text { Median } & \text { Filter } \\
(\mathrm{DMF}) . & & \end{array}$ & $\begin{array}{l}\text { Reduced Gaussian distributed noise and } \\
\text { impulse noise. } \\
\text { DMF helps to join broken fingerprint } \\
\text { ridges, corrects the holes of fingerprint } \\
\text { images, and smoothes irregular ridges. } \\
\text { Showed good performance in efficiency } \\
\text { and execution time compared to the } \\
\text { similar type of algorithms. }\end{array}$ \\
\hline $\begin{array}{l}\text { Teddy and } \\
\text { Martin } \\
(2002)[20]\end{array}$ & $\begin{array}{l}\text { Level } 1 \quad \& \\
\text { Level } 2\end{array}$ & $\begin{array}{l}\text { Nonlinear filters, Frequency } \\
\text { domain filter, High pass } \\
\text { Butterworth filter, adaptive } \\
\text { fast Fourier transform }\end{array}$ & $\begin{array}{l}\text { Handles efficiently images of a type like } \\
\text { blurred, incomplete or partial and un } \\
\text { clear spatial definition. }\end{array}$ \\
\hline $\begin{array}{l}\text { E-Kyung } \\
\text { and Bae } \\
(2006)[21]\end{array}$ & Level 1 & $\begin{array}{l}\text { Adaptive Filtering, mean, } \\
\text { variance, block directional } \\
\text { difference, ridge and valley } \\
\text { thickness ratio, and } \\
\text { orientation change }\end{array}$ & $\begin{array}{l}\text { Able to recognize and enhance different } \\
\text { conditions of input image, which are oil, } \\
\text { dry, and neutral instead of uniform } \\
\text { image.yu }\end{array}$ \\
\hline $\begin{array}{l}\text { Chengpu et } \\
\text { al. (2008) } \\
{[22]}\end{array}$ & Level 1 & $\begin{array}{l}\text { Contrast stretching, tensor } \\
\text { property, Gabor filter and } \\
\text { diffusion filter }\end{array}$ & $\begin{array}{l}\text { Improves the clarity between foreground } \\
\text { and background of the fingerprint } \\
\text { image. } \\
\text { Improves the orientation estimation. } \\
\text { Takes the advantages of both Gabor } \\
\text { filter and diffusion filter. }\end{array}$ \\
\hline $\begin{array}{l}\text { Wang, Li, } \\
\text { Huang, \& } \\
\text { Feng, 2008 } \\
\text { [23] }\end{array}$ & $\begin{array}{l}\text { Level } 1 \& \\
\text { Level } 2\end{array}$ & Log Gabor filter & $\begin{array}{l}\text { Overcomes the drawbacks of traditional } \\
\text { Gabor filter } \\
\text { Improves fingerprint enhancement } \\
\text { performance. }\end{array}$ \\
\hline $\begin{array}{l}\text { Yuanyuan } \\
\text { (2012) [24] }\end{array}$ & $\begin{array}{l}\text { Level } 1 \& \\
\text { Level } 2\end{array}$ & Elliptical Gabor filter & $\begin{array}{l}\text { The experimental results show that the } \\
\text { precision of minutiae extraction is }\end{array}$ \\
\hline
\end{tabular}




\begin{tabular}{|c|c|c|c|}
\hline & & & $\begin{array}{l}\text { significantly improved. } \\
\text { Improved quality minutiae result in good } \\
\text { and higher accuracy rate of the } \\
\text { subsequent operations are also } \\
\text { improved. }\end{array}$ \\
\hline $\begin{array}{l}\text { Babatund } \\
\text { (2012) [25] }\end{array}$ & Level 1 & $\begin{array}{l}\text { Modified sub-models of } \\
\text { mathematical model- } \\
\text { Segmentation, Normalization, } \\
\text { Ridge orientation estimation, } \\
\text { Ridge frequency estimation, } \\
\text { Gabor filtering, and } \\
\text { Binarisation and Thinning }\end{array}$ & $\begin{array}{l}\text { The new version of modified sub- } \\
\text { models of mathematical models } \\
\text { performed well in terms of efficiency } \\
\text { and some other commonly used } \\
\text { performance evaluation matrices. }\end{array}$ \\
\hline $\begin{array}{l}\text { Saatci \& } \\
\text { Tavsanoglu } \\
\text { (2003) [26] }\end{array}$ & Level 1 & $\begin{array}{l}\text { Segmentation, Directional } \\
\text { filter, } \\
\text { Cellular Neural Network } \\
\text { (CNN) Gabor type filters }\end{array}$ & $\begin{array}{l}\text { Resulted in effective fingerprint ridge } \\
\text { enhancement. } \\
\text { High performance. }\end{array}$ \\
\hline $\begin{array}{l}\text { He, Tian, } \\
\text { Luo, \& } \\
\text { Zhang, } \\
\text { (2003) [27] }\end{array}$ & $\begin{array}{l}\text { Level } 1 \quad \& \\
\text { Level } 2\end{array}$ & $\begin{array}{l}\text { Orientation fields as ridge } \\
\text { information, variable } \\
\text { boundary boxes, } \\
\begin{array}{l}\text { alignment method } \\
\text { almple }\end{array}\end{array}$ & $\begin{array}{l}\text { Orientation fields as ridge information, } \\
\text { variable sized boundary boxes, simple } \\
\text { alignment method are three important } \\
\text { aspects. } \\
\text { Overcomes the problem of reference } \\
\text { point per selection with low } \\
\text { computational cost. } \\
\text { Robust to nonlinear deformation } \\
\text { between fingerprints. } \\
\text { Reduces the complexity of alignment. }\end{array}$ \\
\hline
\end{tabular}

\section{CONCLUSION :}

Fingerprint image enhancement is one of the important steps in Automatic Fingerprint Identification System. The fingerprint recognition system performance always depends on the quality of fingerprint input image. Fingerprint image enhancement is technically done by improving the quality of ride pattern or increasing the consistency of ridge orientation, which literally means level 1 feature, is exposed and analyzed. Ridge ending and ridge bifurcation or minutiae points are level 2 features, which is also sometimes exposed and analyzed for enhancement purpose. In this paper, we have surveyed earlier works in fingerprint image enhancement of about 21 authors. The different methods used for image enhancement are wavelet transform, Gabor Filter, Log Gabor filter, Directional filter, Elliptical Gabor filter, Adaptive Filtering and much more similar types of filtering techniques. All the 21 authors focus on image enhancement techniques and depict that its very essential in order to get high quality in image recognition or automatic matching process, especially in noisy, wound or damaged fingerprint image.

\section{REFERENCES :}

[1] Virdi, M. K. (2014). Fingerprint Matching System for Spurious Minutiae. Journal of Basic and Applied Engineering Research, 1(11), 50-53.

[2] Dermatoglyphics.org. (2017). 11 Basic Patterns of Fingerprint [online] Available at: http://dermatoglyphics.org/11 Basic Patterns of Fingerprint / [Accessed 17 July. 2017].

[3] Karani, K. P., Aithal, P. S. (2017). A Conceptual Study on Image Enhancement Techniques for Fingerprint Images. International Journal of Applied Engineering and Management Letters (IJAEML),1(1), 63-72. DOI: http://dx.doi.org/10.5281/zenodo.831678 
[4] Krishna Prasad, K. and Aithal, P. S.(2017). A Conceptual Study on User Identification and Verification Process Using Face Recognition Techniques. International Journal of Applied Engineering and Management Letters (IJAEML), (ISSN Applied), 1(1), 6-17. DOI:http://doi.org/10.5281/zenodo.810343.

[5] https://images.google.com/. (2017). Google. [online] Available at: https://images.google.com/ Low level features of fingerprint [Accessed 18 July. 2017].

[6] https://images.google.com/. (2017). Google. [online] Available at: examples of level 2 features of fingerprint [Accessed 19 July. 2017].

[7] Sherlock, B. G., Monro, D. M., \& Millard, K. (1994). Fingerprint enhancement by directional Fourier filtering. IEE Proceedings-Vision, Image and Signal Processing, 141(2), 87-94.

[8] Chikkerur, S., Cartwright, A. N., \& Govindaraju, V. (2007). Fingerprint enhancement using STFT analysis. Pattern recognition, 40(1), 198-211.

[9] Hsieh, C. T., Lai, E., \& Wang, Y. C. (2003). An effective algorithm for fingerprint image enhancement based on wavelet transform. Pattern Recognition, 36(2), 303312.

[10] Paul, A., \& Lourde, R. (2006). A Study on Image Enhancement Techniques for Fingerprint Identification. 2006 IEEE International Conference on Video and Signal Based Surveillance. https://doi.org/10.1109/AVSS.2006.14

[11] Ye, Z., Mohamadian, H. and Ye, Y. (2007) Information Measures for Biometric identification via 2D Discrete Wavelet Transform, Proceedings of the 3rd Annual IEEE Conference on Automation Science and Engineering Scottsdale, AZ, USA, Pp. 22- 25

[12] Farina, A., Kovacs-Vajna, Z. M., \& Leone, A. (1999). Fingerprint minutiae extraction from skeletonized binary images. Pattern recognition, 32(5), 877-889.

[13] Maio, D., \& Maltoni, D. (1997). Direct gray-scale minutiae detection in fingerprints. IEEE transactions on pattern analysis and machine intelligence, 19(1), 27-40.

[14] Jain, A. K., Hong, L., Pankanti, S., \& Bolle, R. (1997). An identity-authentication system using fingerprints. Proceedings of the IEEE, 85(9), 1365-1388.

[15] Gabor, D. (1946) Theory of communication, Journal of IEE, 92, 429457.

[16] Hong, L., Jain, A.K., Pankanti, S. and Bolle, R. (1996) Fingerprint enhancement IEEE, 5, 202-207.

[17] Yang, J., Liu, L., Jiang, T., \& Fan, Y. (2003). A modified Gabor filter design method for fingerprint image enhancement. Pattern Recognition Letters, 24(12), 18051817.

[18] Greenberg, S., Aladjem, M., Kogan, D., \& Dimitrov, I. (2000). Fingerprint image enhancement using filtering techniques. In Pattern Recognition, 2000. Proceedings. 15th International Conference on (Vol. 3, pp. 322-325). IEEE.

[19] Wu, C., Shi, Z., \& Govindaraju, V. (2004). Fingerprint image enhancement method using directional median filter. In Proc. of SPIE (Vol. 5404, p. 67).

[20] Teddy, K. and Martin, L. (2002) Fingerprint Enhancement by spectral analysis techniques, Proceedings of 31st Applied Imagery Pattern Recognition workshop, Pp 133-139.

[21] Yun, E. K., \& Cho, S. B. (2006). Adaptive fingerprint image enhancement with fingerprint image quality analysis. Image and Vision Computing, 24(1), 101-110.

[22] Chengpu, Y., Mei, X. and Jin, Q. (2008) An effective and robust fingerprint enhancement method, IEEE International 
Symposium on computational Intelligence and Design, 7, 110-113.

[23] Wang, W., Li, J., Huang, F., \& Feng, H. (2008). Design and implementation of LogGabor filter in fingerprint image enhancement. Pattern Recognition Letters, 29(3), 301-308. https://doi.org/10.1016/j.patrec.2007.10.004

[24] Yuanyuan, Z. (2012). Fingerprint image enhancement based on elliptical shape Gabor filter. 2012 6th IEEE International Conference Intelligent Systems, 344-348. https://doi.org/10.1109/IS.2012.6335240.

[25] Babatunde, I. G. (2012). Fingerprint Image Enhancement : Segmentation to
Thinning.(IJACSA) International Journal of Advanced Computer Science and Applications, 3(1), 15-24.

[26] Saatci, E., \& Tavsanoglu, V. (2003). Fingerprint image enhancement using CNN filtering techniques. International Journal of Neural Systems, 13, 453-460. https://doi.org/10.1142/S012906570300173 $\underline{X}$.

[27] He, Y., Tian, J., Luo, X., \& Zhang, T. (2003). Image enhancement and minutiae matching in fingerprint verification. Pattern Recognition Letters, 24(9-10), 1349-1360. https://doi.org/10.1016/S01678655(02)00376-8. 